\title{
Epididimitis tuberculosa aislada
}

\author{
Isolated tuberculous epidydimitis
}

Bouchentouf Rachid ${ }^{1}$ y Ghoundale Omar $^{2}$

Varón de 36 años de edad, marinero sin antecedentes de tuberculosis pulmonar ni exposición a pacientes bacilíferos. Acudió a consulta por orquialgia derecha moderada e intermitente de 2 meses de evolución con fístulas cutáneas, inicialmente tratado con ceftriaxona $500 \mathrm{mg}$ por vía intramuscular en dosis única y doxiciclina $200 \mathrm{mg}$ /día durante 10 días.

Al examen físico se observó una masa consistencia dura dolorosa a la palpación al nivel de la región caudal del epidídimo derecho asociada a múltiples fístulas cutáneas (Figura 1).

En los exámenes auxiliares: hemograma con 7.800 leucocitos por $\mathrm{mm}^{3}$, neutrófilos $65 \%$, linfocitos $29 \%$, hemoglobina $10 \mathrm{~g} / \mathrm{dl}$, proteína $\mathrm{C}$ reactiva $19 \mathrm{mg} / \mathrm{dl}$.

La serología para el VIH fue negativa y la radiografía de tórax fue normal.

La determinación de marcadores tumorales y el examen general de orina fueron normales.

La ecografía escrotal mostró un cambio heterogéneo en el epidídimo derecho.

Se realizó epididimectomía parcial (caudal) con resección del trayecto fistuloso (Figuras 2 y 3 ).

El estudio del tejido tomado reveló la presencia de granulomas con células epitelioides y con

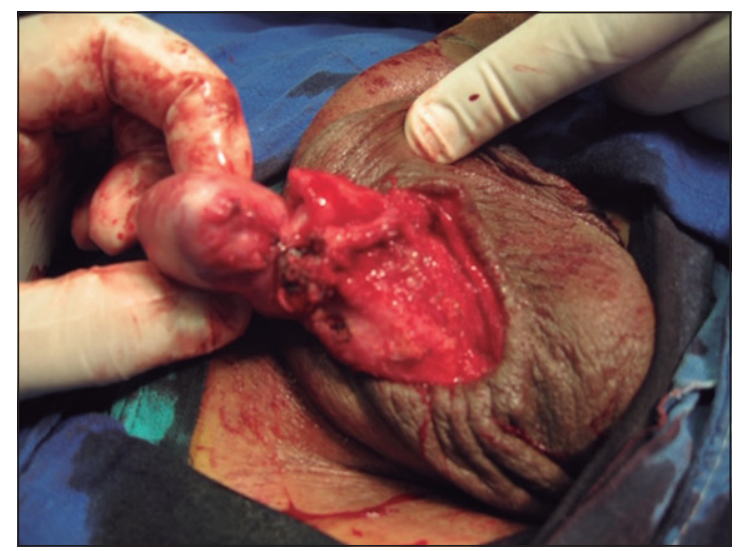

Figura 2. Intraoperatorio de epididimectomía parcial cauda derecha necrosis caseosa, tinción Ziehl-Neelsen positiva para bacilos ácido-alcohol resistentes. Se inició un tratamiento para tuberculosis con lo que se observó evolución favorable.

La tuberculosis genitourinaria es una presentación poco común de la tuberculosis y supone $4 \%$ de las tuberculosis extrapulmonares. Es más frecuente en los hombres jóvenes sexualmente activos y el

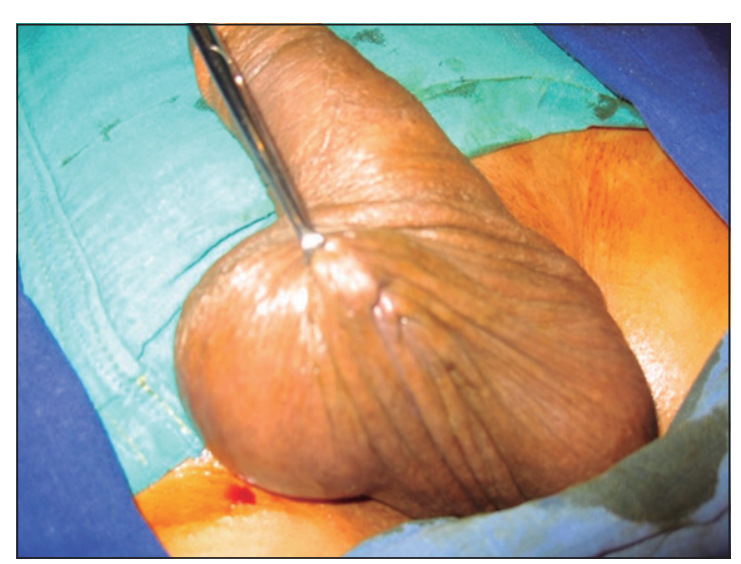

Figura 1. Imagen intraoperatoria, múltiples fístulas cutáneas.

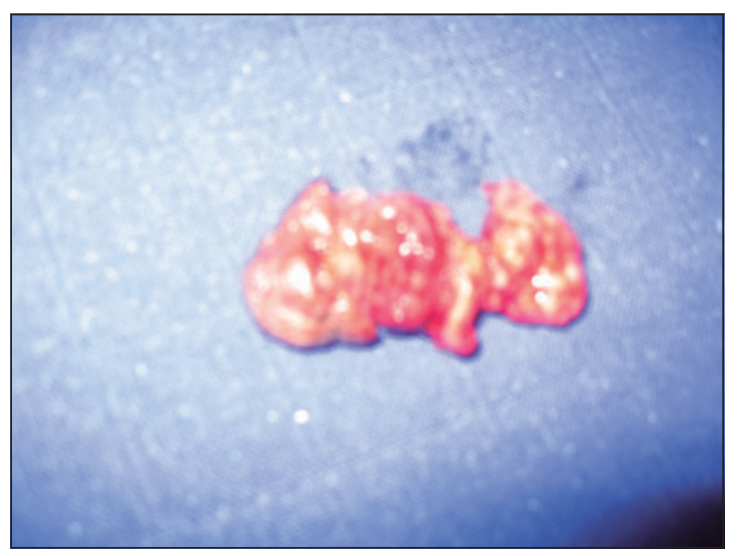

Figura 3. Pieza operatoria resecada.
'Servicio de Neumología. Hospital Militar Avicena, Marrakech. Marruecos. 2Servicio de Urología. Hospital Militar Avicena, Marrakech. Marruecos.

Recibido 2020-08-04 y aceptado 2020-08-11

Correspondencia a: Dr. Rachid Bouchentouf rachidbouchentouf 513@ gmail.com 
sitio de presentación es el epidídimo principalmente la cola.

En la mayoría de los casos se desarrolla a partir de la propagación retrógrada de los bacilos tuberculosos desde el tracto urinario afectado. La epididimitis tuberculosa se asocia a afectación renal concomitante en el $80 \%$ de los casos. La presencia de inflamación escrotal con hidrocele es la regla en esta enfermedad y puede ser tanto aguda como crónica. La presencia de fístulas cutáneas en los procesos avanzados es posible.

\section{Responsabilidades éticas}

Protección de personas y animales. Los autores declaran que para esta investigación no se han realizado experimentos en seres humanos ni en animales.

Confidencialidad de los datos. Los autores declaran que en este artículo no aparecen datos de pacientes.

Conflictos de interés: no hay.

\section{Bibliografía}

1. Singh JP, Priyadarshi V, Kundu AK, Vijay MK, Bera MK, Pal DK.

Genito-urinary tuberculosis revisited: 13 years experience of a single centre.
Indian J Tuberc. 2013;60:

15-22.

2. Chen SM. Isolated tuberculous epididymitis. Formos J Surg. 2017; 50:74-6.

3. Mahaveer J, Weston, Wolstenhulme S.
Epidydimal tuberculosis: A diagnostic challenge, sonographic findings, and differential diagnosis. Journal of Diagnostic Medical Sonography 2018;34:59-63. 